\title{
Effects of caudate stimulation on classical leg flexion conditioning*
}

\author{
SHELDON I. PLUMER \\ Idaho State L'niversity, Pocatello, Idaho 83201 \\ and \\ JEROME SIEGEL and GEORGE A. CICALA \\ University of Delaware, Newark, Delaware 19711
}

\begin{abstract}
The effects of low-frequency caudate stimulation on classical leg flexion conditioning in cats were assessed. During acquisition, conditioned leg flexion was markedly impaired by caudate stimulation while the unconditioned leg flexion response was unaffected. On trials immediately following the discontinuation of caudate stimulation, asymptotic performance of conditioned leg flexion occurred. These differential inhibitory effects on learning and performance were interpreted as supporting the contention that the caudate nucleus influences the behavior of cats by modulating the elaboration of goal-directed motor responses.
\end{abstract}

Low-frequency stimulation of the caudate nucleus has been found to induce electrographic synchrony and inhibition of behavior. Complex, recently learned, and incompletely learned tasks were most susceptible to caudate inhibition, while simple, reflexive, and overlearned reactions were relatively unaffected (Buchwald, Wyers, Carlin, \& Farley, 1961 a; Buchwald \& Hull, 1967; Buser, Rougeul, \& Perret, 1964; Kitsikis \& Rougeul, 1968).

While the incidence of caudate-induced behavioral inhibition has been well documented, the cause of this inhibition has been difficult to characterize. Several investigations have reported that caudate stimulation interfered with the learning capability of rats by disrupting the formation of memory traces. When low-frequency caudate stimulation was presented after an instrumental conditioning trial, retrograde amnesia was produced for that learning experience (Wyers, Peeke, Williston, \& Herz, 1968; Peeke \& Herz, 1971; Herz \& Peeke, 1971; Wyers \& Deadwyler, 1971). On the other hand, the behavioral effects which have been induced in cats by caudate stimulation may not be due to its disruption of memory processing. Wilburn and Kesner (1972) found that low-frequency caudate stimulation produced inconsistent amnestic effects in cats when it was administered after an instrumental conditioning trial.

Each of these instrumental conditioning studies employed a retrograde amnesia paradigm to investigate the influence of caudate stimulation on the development of associations, because stimulation presented during the acquisition trial would have inhibited the enactment of the response that was to be conditioned, and learning would have been precluded. The retrograde amnesia paradigm was used to insure the occurrence of the Siegel. response that was to be conditioned (Peeke \& Herz, 1971). Since the brain stimulation was presented after the conditioning trial was completed, the previous studies (Wyers et al, 1968; Wilburn \& Kesner, 1972; Peeke \& Herz, 1971; Herz \& Peeke, 1971: Wyers \& Deadwyler, 1971) investigated the influence that caudate stimulation had on the consolidation of memory traces related to learning. The effects of the low-frequency stimulation on the formation of associative processes occurring during the trial could not be determined.

The purpose of the present experiment was to undertake a more direct investigation of the influence that low-frequency caudate stimulation had on associative processing. To accomplish this goal, a classical conditioning paradigm was utilized. During classical conditioning, the $\mathrm{S}$ does not actively manipulate the environment. When an appropriate conditioned stimulus (CS) and unconditioned stimulus (US) are presented to the $S$ in a proper temporal sequence, associations will form between the afferent patterns of activity produced by the CS and US, and learning will occur (Kling, 1972). Caudate stimulation does not interfere with reflex actions or sensory and perceptual processing in cats (Buchwald, Horvath, Soltysik, \& Romero-Sierra, 1964; Buser et al, 1964). Therefore, it was anticipated that associative processing could occur in cats during a classical conditioning trial even if the caudate stimulation inhibited the motor elaboration of the conditioned responding (CRs). Classical leg flexion conditioning was utilized because preliminary research had indicated that the unconditioned leg flexion response (UR) was unaffected by caudate stimulation and because leg flexion was readily conditioned in cats (McAdam, Knott, \& Chiorini, 1965). Hence, classical leg flexion conditioning would make it possible to determine whether a skeletal response could be conditioned when caudate stimulation was presented throughout every acquisition trial. 


\section{METHOD}

\section{Subjects and Apparatus}

The Ss were six female cats weighing between 2.2 and $3.5 \mathrm{~kg}$. They were housed individually in standard metal cages with a 12-h light, 12-h dark cycle and were given ad lib access to food and water.

All conditioning was conducted in a sound-attenuating, electrically shielded, ventilated Industrial Acoustics walk-in chamber illuminated by a $60-\mathrm{W}$ shaded lamp. Each $\mathrm{S}$ was placed in a rubber restraining harness, which restricted all but simple head movements and leg flexions. The harnessed $S$ was supported in a canvas sling and suspended from a steel frame inside the chamber. Screw clamp electrodes were attached to the skin between the footpad of the S's left hind leg. A Grass S-4 stimulator and SIU stimulus isolation unit were used to generate an unavoidable $150-\mathrm{V} 100-\mathrm{msec}$ dc pulse. This US was used to elicit unconditioned leg flexions via the screw clamp electrodes (Chiorini, personal communication, 1969). One end of a $22.40-\mathrm{kg}$ test nylon thread was taped to the left hind leg of the $\mathrm{S}$, and the other end was anchored to an E\&M Model c-105, $30-300-g$ photobeam-breaking pressure transducer. Leg flexions were recorded on an E\&M physiograph which contained a Mark VII amplifier. A Hewlett-Packard $200 \mathrm{AB}$ audio-oscillator produced a $600-\mathrm{msec} 80-\mathrm{dB}$ (re .0002 dynes $/ \mathrm{cm}^{2}$ ) white noise $\mathrm{CS}, 30 \mathrm{~dB}$ over the ambient noise level of the chamber, through a speaker placed $30 \mathrm{~cm}$ above and $115 \mathrm{~cm}$ directly in front of the head of the suspended S. A Grass SD-5 stimulator and CCUIA constant current unit provided the caudate nucleus stimulation. Electrophysiological recordings were made on a Grass Model III D electroencephalograph. All of the events were programmed through Massey Dickenson panel logic units.

\section{Surgery}

Each $\mathrm{S}$ was anesthetized with sodium pentobarbital $(38 \mathrm{mg} / \mathrm{kg}$, IP) and held in a Trent-Wells stereotaxic instrument. During the course of the operation, pressure points from the stereotaxic frame and wound edges were infiltrated with $2 \%$ procaine. After a midline incision was made, the skull was exposed and burr holes were drilled for surface and deep electrode placements. Stereotaxic coordinates for electrode placements were obtained from the atlas of " Jasper and Ajmone-Marsan (1954). Surface recording electrodes were constructed from stainlèss steel panthead screws $(2-56 \times 1 / 8)$, which were threaded through the skull over the anterior sigmoid gyrus (bilateral placement). In addition, an indifferent electrode was threaded over the left frontal sinus, and a ground electrode was located over the right cerebellar hemisphere. Twenty-four-gauge concentric bipolar stainless steel electrodes (outer diam, $0.5 \mathrm{~mm}$; tip separation, $2.0 \mathrm{~mm}$ ) were implanted bilaterally in the head of the caudate nucleus (Jasper and Ajmone-Marsan coordinates, F 15.5, L 4.5, H 5.5) through the burr holes. Previously, the electrodes had been coated and baked with three layers of Epoxylite and $1.0 \mathrm{~mm}$ was bared from both the tips and the barrels. Furthermore, 34-ga insulated stainless steel wires had been soldered to each electrode prior to implantation, and the connections were insulated with Epoxylite. The surface and deep electrodes were affixed to the skull with Caulk aneuroplastic cement. Amphenol 220-P02 "reliatac" male connectors were crimped to the uninsulated distal tips of the 34-ga leads and inserted into a 19-pin Amphenol 222-22N19 female receptacle. The Amphenol receptacle was mounted on the skull with stainless steel anchor screws (2-56 x 1/8) and Caulk aneuroplastic cement, the incision was sutured, and each $\mathrm{S}$ was given a 1.3-cc intramuscular injection of crysticillin ( 400,000 units).

At the conclusion of the experiment, each $\mathrm{S}$ was administered an overdose of sodium pentobarbital. A constant anodal current
( $1 \mathrm{~mA}$ for $20 \mathrm{sec}$ ) was used to produce electrolytic lesions which marked the sites of stimulation. The brain was removed and placed in a solution of $10 \%$ Formalin and potassium ferrocyanide for $24 \mathrm{~h}$. Potassium ferrocyanide reacted with the electrolytically deposited iron particles and produced a Prussian blue stain at the edges of the lesion. The stimulation sites were identified histologically, using frozen 100-micron sections (Siegel, 1968), which were projected onto the atlas of Snider and Niemer (1961).

\section{Postoperative Testing}

After a 3-week recovery period, each $\mathrm{S}$ was placed in the experimental chamber and postoperative tests were conducted to verify functionally the caudate nucleus electrode placements. A cable constructed of Microdot wires, which terminated in a 19-pin Amphenol 222-11N19 male plug, was connected to the Amphenol receptacle mounted on the S's skull. Bilateral caudate stimulation was delivered via the leads in the Microdot cable in parallel to deep electrodes with comparable resistances. Thus, each site of stimulation received half of the current that was generated. Other leads in the cable were connected to the surface electrodes and were used to record cortical activity. Monopolar recordings were made with the use of the indifferent electrode that was located over the left frontal sinus. Bipolar recordings were made across the cerebral hemispheres between the left and right anterior sigmoid gyri.

In every S, 1-pps trains of monophasic stimulation (1.0-msec pulse width) elicited the "caudate-spindle" (Buchwald, Wyers, Laurprecht, \& Heuser, 1961b) over the anterior sigmoid gyrus. Current intensities required to produce spindling varied from $S$ to $S(1.0-2.5 \mathrm{~mA})$. Previous research had indicated a correlation between the "caudate-spindle" and behavioral inhibition induced by low-frequency caudate stimulation. However, a causal relationship has not been demonstrated (Buchwald \& Hull, 1967). Therefore, following the electrophysiological confirmation, a behavioral test was conducted to verify further the electrode placements. Each $S$ was placed on a $231 \frac{1}{2}-\mathrm{h}$ food-deprivation schedule, and the caudate nucleus was stimulated at 6 pps $(0.5-1.0-\mathrm{msec}$ pulse width) at various times during a $1 / 2-h$ feeding period. When the current was raised over each S's spindle threshold $(2.0-3.5 \mathrm{~mA})$, the stimulation inhibited the $S$ from continuing spontaneous eating. Motor disturbances were never observed during these preliminary tests. The caudate stimulation did not cause any cheling, forced head turning, or muscle spasms. Moreover, the $S$ was not immobilized as in the "arrest reaction" (Hunter \& Jasper, 1949). While being inhibited from eating, each $S$ remained poised over the food dish, and was able to make simple reactions, such as orienting.

\section{Experimental Procedure}

Prior to conditioning, each $\mathrm{S}$ was adapted to being harnessed and supported in the canvas sling while the recording and stimulating devices were attached to its left hind leg. On the day after adaptation was completed, each $S$ was given 10 presentations of the CS alone, after which it received 40 CS-US pairings. The US was presented during the last $100 \mathrm{msec}$ of the CS. The intertrial interval varied irregularly between $30 \mathrm{sec}$ and $2 \mathrm{~min}$. On the second and third days of conditioning, each $\mathrm{S}$ received $50 \mathrm{CS}$-US pairings, and on the fourth conditioning day, 10 more pairings were administered for a total of 150 conditioning trials. The conditioning procedure was designed after Crespi (1944), using a crossover arrangement which enables a separate evaluation of the effects that caudate stimulation had on learning and performance. This design permitted the detection of conditioning despite the absence of CRs during the acquisition trials. Thus, the Ss were randomly divided into two groups of three Ss each. and the order in which the Ss were run was counterbalanced. The Ss in Group 1 (CD-39, CD-47. and 
(D-55) reccived low-frequency caudate stimulation (6 pps, $0.5-1.0$-msec pulse width) on each of the 150 conditioning trials at an intensity just subthreshold for the production of motor interference (3.5-6.5 $\mathrm{mA})$. The caudate stimulation was initiated $20 \mathrm{sec}$ prior to the onset of the CS and was maintained until $10 \mathrm{sec}$ after the CS-US sequence terminated. The Ss in Group 2 (CD-26, CD-43, and CD-46) did not receive caudate stimulation during the 150 training trials. Immediately after the 10th conditioning trial on the fourth day (150th trial), the crossover was imposed, i.e., the brain stimulation conditions of the two groups were switched. For 30 additional testing trials, the Ss in Group 2 received low-frequency caudate stimulation (6 pps, $0.5-\mathrm{msec}$ pulse width) at an intensity just below the threshold for motor interference (5.0-6.0 mA), while the Ss in Group 1 were run for 30 additional testing trials without caudate stimulation.

Following these last 30 testing trials, the McAdam, Knott, and Chiorini (1965) procedure for the specification of the CR was initiated. Each $S$ was given 10 presentations of the US alone, and the shortest leg flexion reaction time in these trials was used to determine the minimum latency of the UR for that particular S. Leg flexions in the previous 180 trials occurring after the onset of the CS and having a latency shorter than the fastest UR made during these 10 trials of the US alone were considered CRs.

\section{RESULTS}

\section{Histological Findings}

The electrode tip placements are summarized in Fig. 1, which is a tracing of frontal plane F 16.0 from the atlas of Jasper and Ajmone-Marsan (1954). Buchwald et al (1964) and Buchwald, Hull, and Trachtenberg (1967) found that the critical dimension concerning the inhibitory effectiveness of the site of caudate stimulation was the position of the electrode in the lateral plane within the head of the caudate nucleus. Since all of the electrodes were within $\pm 0.5 \mathrm{~mm}$ of

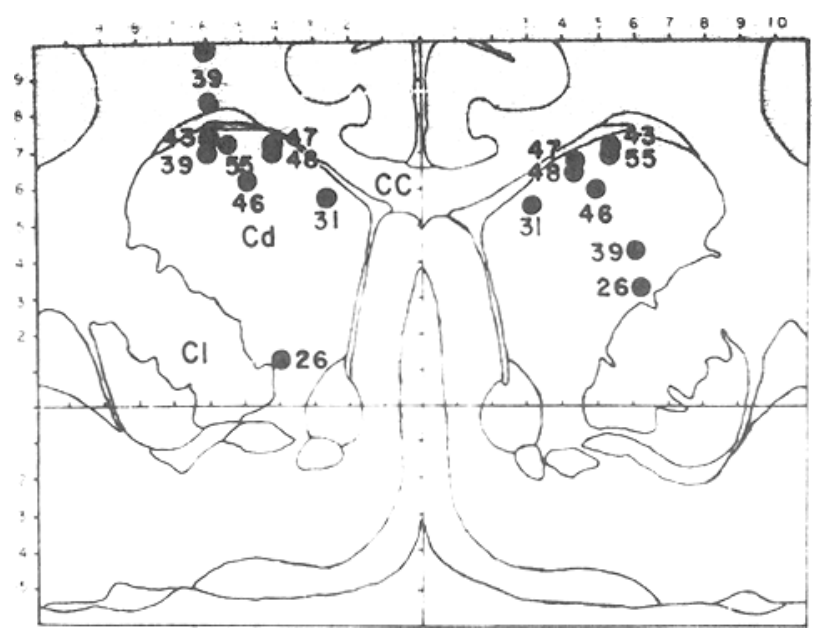

Fig. 1. A tracing from the atlas of Jasper and Ajmone-Marsan (1954). The symbols represent the lesions produced by the constant anodal current. The numbers next to the symbols identify the Ss. The two most dorsal lesions in the left hemisphere of S CD-39 were due to breaks in the insulation of the electrode. Ss CD-31 and CD-48 were not used in the present study. Cd., caudate nucleus; $\mathbf{C C}$., corpus callosum; $\mathrm{CI}$., internal capsule.

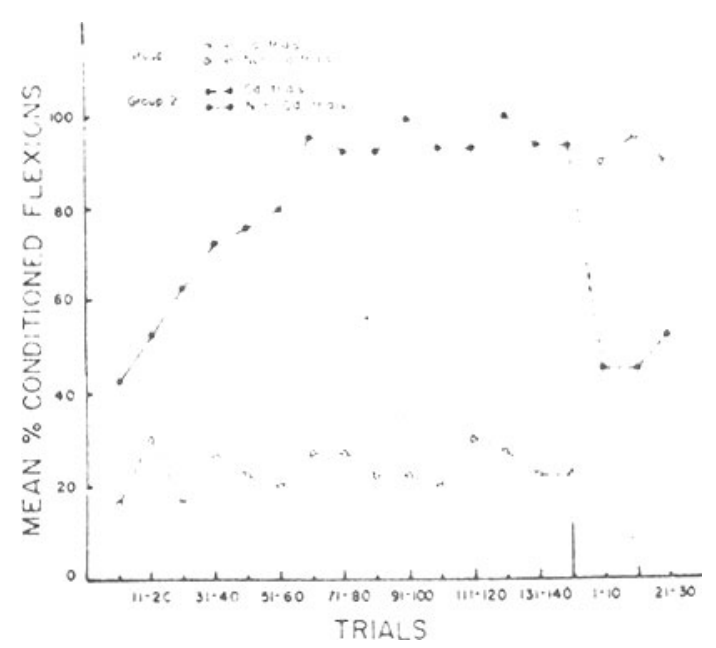

Fig. 2. The effects of low-frequency caudate stimulation on the learning and performance of classical leg flexion conditioning. Ss CD-39, CD-47, and CD-55 were in Group 1; Ss CD-26, CD-43, and CD-46 were in Group 2. Cd trials, caudate trials.

F 16.0, this section was chosen from the atlas as being representative of the frontal plane of the placements. Figure 1 shows that in every $\mathrm{S}$, the electrodes were implanted within the head of the caudate nucleus. The electrode tips in Ss CD-43, CD-46, CD-47, and CD-55 were positioned in the dorsomedial aspect of the caudate nucleus. On the other hand, the tips of both electrodes in CD-26 were located ventrally and on the medial border of the internal capsule. Furthermore, the tip of the right electrode in CD-39 was ventrally and laterally positioned. While the tip of the left placement in CD-39 was dorsomedially positioned, the constant anodal current had also produced lesions in the corpus callosum and corona radiata.

\section{Behavioral Findings}

The percentage of CRs was computed for each $\mathrm{S}$ for each block of 10 trials. The mean percentage of CRs for each group as a function of training trials is shown in Fig. 2. The 10 CS-only adaptation trials were excluded from this figure since no flexion responses occurred in any of the Ss. Figure 2 shows that during the 150 acquisition trials, Group 1, which received caudate stimulation on every trial, did not increase its mean percentage of CRs. S CD-39 was in this group, and its rate of CRs fluctuated between $40 \%$ and $70 \%$, while the other Ss achieved a maximum of only $10 \%$ CRs. Nevertheless, on every trial, the UR was elicited by the presentation of the US. In contrast, a typical acquisition function, similar to that reported by McAdam et al (1965) for classical leg flexion conditioning in cats, was seen in Group 2, which did not receive caudate stimulation during the 150 acquisition trials. The postshift testing data also included in Fig. 2 indicates that the introduction of caudate stimulation produced a 
decrease of more than $40 \%$ in the mean percentage of CRs in Group 2. It should be noted that S CD-26 was in this group and made CRs on every postshift trial, while the other Ss made CRs on 10\%-30\% of the trials. As in Group 1, the caudate stimulation did not prevent the occurrence of the UR. The withholding of caudate stimulation during the 30 postshift trials resulted in a high percentage of CRs by the Ss in Group 1. On the first block of postshift trials, the Ss' rate of CRs increased from a mean fluctuating around $22 \%$ to a mean of $90 \%$ CRs.

\section{DISCUSSION}

Low-frequency caudate stimulation inhibited the performance of a classically conditioned leg flexion response during as well as after acquisition of this CR. Previously, Buchwald et al (1961a) found that the inhibitory influence that caudate stimulation had on a CR diminished after the response was completely learned. Since Buchwald et al (1961a) investigated an instrumentally conditioned behavior, it was necessary to use intensities of stimulation which allowed the Ss to make the CRs. On the other hand, the employment of classical conditioning enabled the use of intensities of stimulation which were just below the levels that produced motor interference. While receiving this stimulation, the Ss could only make reflexive reactions, such as the UR. Hence, the continued inhibitory effectiveness of caudate stimulation observed in Group 2 after acquisition had taken place, was probably due to the high levels of stimulation utilized in the present study.

In spite of receiving caudate stimulation which had inhibited CRs during the preshift trials, the performance rate of Group 1 increased precipitously in the first block of non-caudate trials. The immediacy of CRs indicated that the perceptual and associative processes upon which learning depends had occurred even though the Ss had received high intensities of the synchronogenic stimulation. The sudden decrease in CRs that was noted when Group 2 received caudate stimulation during the postshift trials further supports the contention that performance, rather than learning, is susceptible to the inhibitory influences of caudate stimulation. Furthermore, the $S s$ in the present study received caudate stimulation for $10 \mathrm{sec}$ after the CS-US sequence was terminated. The fact that learning occurred during the preshift trials of Group 1 indicates that the post-CS-US caudate stimulation did not prevent consolidation of the memory traces related to this type of conditioning.

The caudate-induced inhibition of performance was probably modified by the placement of electrodes in the lateral aspect instead of the medial part of the head of the caudate nucleus of one $S$ in each group (CD-39 in Group 1, and CD-26 in Group 2). Buchwald et al (1964. 1967) found that the most effective inhibition of behavior was induced by low-frequency stimulation of the medial area. Stimulation of the internal capsule or the lateral aspect of the head of the caudate nucleus produced motor disturbances and stimulus-bound movements. Thus, the two Ss with inaccurate placements may constitute a control for those Ss with medial placements. As was pointed out in the results section, caudate stimulation did not completely inhibit CRs in the preshift trials of Group 1. The mean percentage level of CRs that was achieved by this group was largely the result of the high performance rate of $S$ CD-39. This $S$ had one inaccurate placement and the barrel of the other electrode was poorly insulated, enabling current to be released into surrounding structures. Similarly, the mean percentage of CRs that was seen during the 30 postshift caudate trials of Group 2 reflected the high performance rate of S CD-26, both of whose electrodes were inaccurately positioned. The weak inhibitory effects that the caudate stimulation induced on the CRs of these two Ss and the strong inhibitory effects elicited in the other Ss, which had dorsomedial placements, support the finding that medial stimulation produces optimal inhibitory effects (Buchwald et al, 1964, 1967).

Previous experiments have reported that while caudate stimulation was inhibiting cats from performing instrumentally conditioned behaviors, it did not disrupt attention, sensory processing (Buchwald et al, 1964; Buser et al, 1964), or perceptual processing (Buser et al, 1964). Recently, Wilburn and Kesner (1972) found that caudate stimulation produced inconsistent amnestic effects in cats. Besides substantiating these earlier findings, the results of the present experiment indicate that caudate stimulation in cats does not prevent the occurrence of learning, but has a pronounced inhibitory influence on the performance of a CR. Thus, contrary to the studies using rats as Ss (Wyers et al, 1968; Peeke \& Herz, 1971; Wyers \& Deadwyler, 1971; Herz \& Peeke, $1971)$, the caudate nucleus in cats does not appear to be exerting its inhibitory influence by disrupting either memory or associative processing. Rather, the caudate nucleus appears to be part of an inhibitory system which modulates the motor elaboration of goal-directed behaviors, whether they are learned (Buchwald et al, 1961a, b, 1964; Buser et al, 1964) or innately organized (Plumer \& Siegel, 1973).

\section{REFERENCES}

Buchwald, N. A., Horvath, F., Soltysik, S., \& Romero-Sierra, C. Inhibitory responses to basal ganglia stimulation. Boletin Institut de Estudios Medicos Biologicos (Mexico), 1964, 22 , 363-377.

Buchwald, N. A., \& Hull, C. D. Some problems associated with interpretation of physiological and behavioral responses to stimulation of caudate and thalamic nuclei. Brain Research. 1967. 6. 1-11.

Buchwald. N. A.,-Hull, C. D.. \& Trachtenberg. M. C. Concomitant behavioral and neural inhibition and 
disinhibition in response to subcortical stimulation. Lxperimental Brain Research. 1967. 4. 58-72.

Buchwald, N. A.. Wyers. E. J.. Carlin. J.. \& Farley, R. L. Lffects of caudate stimulation on visual discrimination. Experimental Neurology, 1961a, 4. 23-36.

Buckwald, N. A.. Wyers. E. J., Laurprecht, C. W.. \& Heuser, G. The "caudate-spindle." IV. A behavioral index of caudate induced inhibition. Llectroencephalography \& Clinical Neurophysiology, 1961b. 13, 531-537.

Buser, P., Rougeul, A.. \& Perret, C. Caudate and thalamic influences on conditioned motor responses in the cat. Boletin Institut de Estudios Medicos Biologicos (Mexico), 1964, 22. 293-307.

Crespi, L. P. Amount of reinforcement and level of performance. Psychological Review, 1944, 51, 341-357.

Herz, M. J., \& Peeke, H. V. S. Impairment of extinction with caudate nucleus stimulation. Brain Research, 1971, 33, 519-522.

Hunter, J., \& Jasper, H. H. Effects of thalamic stimulation in unanesthetized animals. The arrest reaction and petit mal like seizures, activation patterns and generalized convulsions. Electroencephalography \& Clinical Neurophysiology, 1949, 1, 305-324.

Jasper, H. H., \& Ajmone-Marsan, C. A stereotaxic atlas of the diencephalon of the cat. Ottawa: National Research Council of Canada, 1954.

Kitsikis, A., \& Rougeul, A. The effect of caudate stimulation on conditioned motor behavior in monkeys. Physiology \& Behavior, 1968, 3, 831-837.

Kling, J. W. Learning: Introductory survey. In J. W. Kling and L. A. Riggs Eds.), Woodworth \& Schlosberg's Experimental psychology. Vol. II. Learning, motivation, and memory. (3rd ed.) New York: Holt, Rinehart \& Winston. 1972.

McAdam, D., Knott, J. R., \& Chiorini, J. Classical conditioning in the cat as a function of the CS-US interval. Psychonomic Science, 1965, 3, 89-90.

Peeke, H. V. S., \& Herz, M. J. Caudate nucleus stimulation retroactively impairs complex maze learning in the rat. Science, $1971,173,80-82$.

Plumer, S. I., \& Siegel, J. Caudate induced inhibition of hypothalamic attack behavior. Physiological Psychology, 1973, in press.

Siegel, J. A rapid procedure for locating deep electrode placements. Physiology \& Behavior, 1968, 3, 203-204.

Snider, R. S., \& Niemer, W. T. A stereotaxic atlas of the cat brain. Chicago: University of Chicago Press, 1961.

Wilburn, M. W., \& Kesner, R. P. Differential amnestic effects produced by electrical stimulation of the caudate nucleus and nonspecific thalamic system. Experimental Neurology, 1972, $34,45-50$.

Wyers, E. J., \& Deadwyler, S. A. Duration and nature of retrograde amnesia produced by stimulation of caudate nucleus. Physiology \& Behavior, 1971, 6, 97-103.

Wyers, E. J., Peeke, H. V. S., Williston, J. S., \& Herz, M. J. Retroactive impairment of passive avoidance learning by stimulation of the caudate nucleus. Experimental Neurology, $1968,22,350-366$.

(Received for publication January 22, 1973; revision received May 15, 1973; accepted June 1, 1973.) 